\title{
Esquema para una Historia del Pensamiento en México.
}

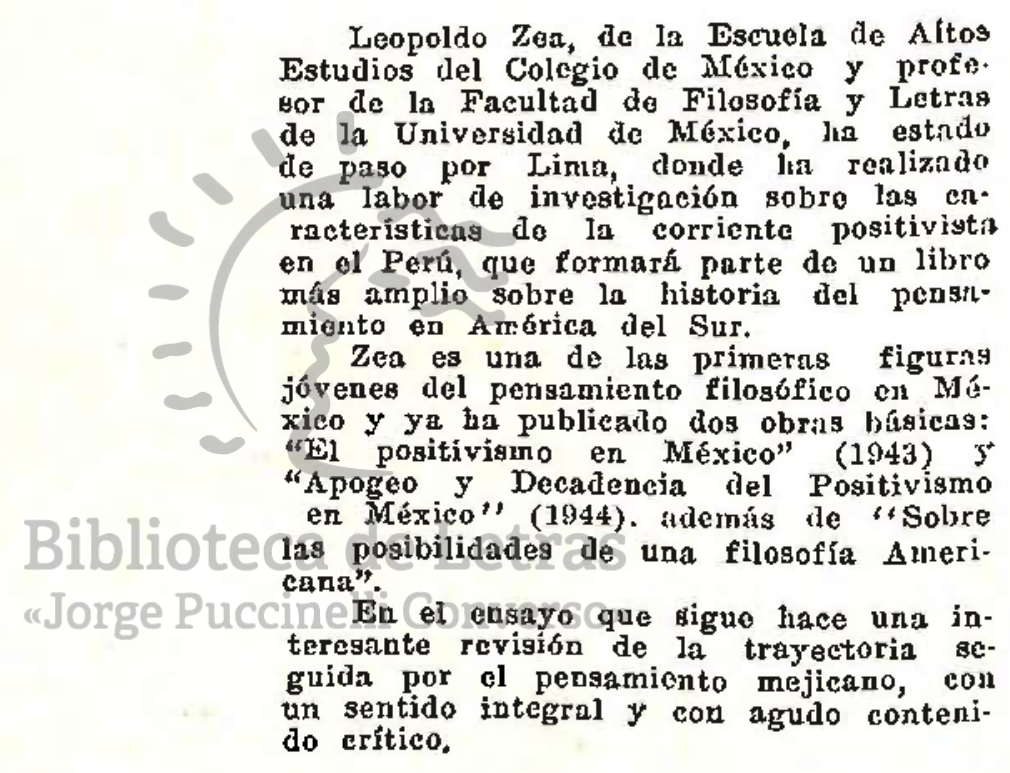

Esquematizar el movimiento de lo que podríamos llathar pensamiento filosófico mexicano, equivale a esquematizar la historia de México, pues, como veremos, existe una estrecha relación entre dicho pensamiento y las peripecias de su historia política y social. Las ideas no se encuentran al margen de los hechos, todo lo contrario, los acompañan como su más legítima expresión. Los hechos plantean los problemas, las ideas tratan de resolverlos. Esta es, me parece, la 


\section{$-243-$}

tarea de toda legítima filosofía. En el caso de México, y lo que digo de mi país puede extenderse al resto de los países americanos, no existe lo que podriamos llamar una filosofía original, si entendemos por filosofía original la creación de determinados sistemas tal como los ha creado Europa; pero sí existe una filosofía propia en cuanto que se ha planteado problemas que le son propios y dado soluciones propias para tales problemas. Lo que no ha sido original es el instrumental para obtener dichas soluciones. En este caso se ha servido del arsenal de ideas que le ha ofrecido la Cultura Europea de la cual es hijo. Pero tales ideas al ser trasladadas a estas nuestras tierras, guardando su forma de origen, se han hecho nuestras al transformar su contenido. Este contenido, vuelvo a repetirlo, es el que le da problemas solamente nuestros.

Nuestra filosofía se presenta así bajo un doble carácter: un carácter pedagógico y un carácter político. Nuestro pensamiento pone el acentó en los problemas que plantean estos temas y trata de resolverlos. El planteamiento de tales problemas tiene su origen en nuestra propia constitución histórica. México, o más ampliamente América, ha surgido a la historia como dependencia Europea. Entra en la Cultura Occidental porque Occidente ha necesitado de ella y la descubre apropiándosela. Con estas tierras Occidente quiso resolver los problemas que lo preocupaban, su crisis histórica. Recuérdese que América entra en la historia de Occidente cuando éste pasa por una de sus grandes crisis, la del nacimiento de la Modernidad y el ocaso del mundo medioeval. La pugna entre estas fuerzas en lucha es llevada a nuestras tierras, una tratando de hacer de América el mundo del futuro, otra un mundo donde el pasado permanezca. Esta pugna llevada a América la han visto con acierto pen- 
sadores de estas tierras. En dicha pugna a los paises Iberoamericanos les tocó ser dependencia de la fuerza que entralba en el ocaso. España trajo a estos países su estática concepción de un mundo apoyado en la divinidad, hacienclo de esta América, por ella conquistada, un último baluarte de su fé; baluarte bien cerrado para que no entrase en él la semilla destructora del modernismo. Esta deberá ser la obra de la Colonia. El Imperio español establecer un cerco político $y$ social, la iglesia un cerco mental. La correlación entre ambos es lógica : el orđen social dependerá en toclo caso de la mentalidad de sus asociados. Para que en un orden social y político fuese estable era menester educar a sus individuos en el respeto a dicho orden. Así el orden político y social impuesto por España tenía como base una pedagogía que imponía al colonial el respeto a dicho orden. Así nacla tenía de extraño que los hombres que lucharon por alcanzar la independencia de estas tierras hayan opuesto a tal manera de pensar una filosofía política y una pedagogia que sostuviesen principios opuestos. Había que transformar el orden social y político; pero antes habia que transformar a sus hombres. Para alcanzar una auténtica independencia no bastaba separarse de la Metrópoli, era menester, además, cambiar los hábitos por ella impuestos. Nuestros pensadores serán así políticos y pedagogos. Repartirán su vida entre la tribuna, el campo de batalla o el atula. Serán a la vez estadistas y maestros. Como he dicho desde un principio, esto vale para toda nuestra América, díganlo sino los nombres de Barreda y Sierra en México; Sarmiento y Alberdi en Argentina; Bilbao y Lastarria en Chile; Rodó en el Uruguay; José de la Luz y Caballero en Cuba. Así como otros muchos más en tođa nuestra América. 
El pensamiento mexicano va a ser un fiel reflejo de la lucha entablada contra la Colonia y los hábitos por ella establecidos. España había impuesto un orden político, un orden mental y un orden social. La independencia había de realizarse frente a estos tres órdenes. La revolución de 18 Io obtendría la Independencia política de México, pero tal independencia no bastaría. Porque si bien México se indeperidizaba políticamente de la Metrópoli no lo hacía en los otros dos aspectos señalados. El clero seguía dominando sobre la conciencia de los mexicanos al reconocerse la religión católica como religión del estado. En cuanto al orden social, el establecido por la Colonia permanecía. Este orden lo daba el dominio de la tierra. Los herederos del conquistador y el clero usufructuaban las tierras mexicanas de las cuales habían despojado a sus naturales. La tierra y el que la trabajaba pertenecían a estos señores feudales de la Colonia. La Independencia frente a España no había cambiado la situación, tan sólo había aumentado el número de terratenientes; al reconocido por la Colonia se había sumado el caudillo militar que había intervenido en la revolución. Una segunda revolución "será la llamada de Reforma," que alcanzará su expresión en la Constitución đe $\mathrm{I}_{557}$, de la que fué paladín nuestro gran patricio Benito Juárez. Por medio de ella se alcanzó lo que podríamos llamar la libertad de conciencia. La Iglesia fué separada del Estado y sus bienes desamortizados. La religión católica dejó de ser religión de Estado; los mexicanos podían pensar libremente. Pero el orden social no fué ni pudo ser reformado. Se quitó a la Iglesia los bienes raíces que poseía, fué desposeída de sus tierras; pero estas no volvieron a sus auténticos dueños, a los que las trabajaban. Las tierras pasaron a los denunciantes que especulaban con ellas, formándose nuevos y poderosos 
latifundios. El latifundista mexicano se hizo dueño y señrs de la economía mexicana y con ella del orden político y social de México. En I91o estallaría una nueva revolución, cien años después de la revolución política. Esta última revolución atacará la base del orden social establecido desde la Colonia, la Tierra. Tierra y Libertad será el grito de la nueva revolución. La tierra tenía que ser para quien la trabajaba. Es en esta fase revolucionaria que nos encontramos, aún no podemos decir que haya concluido, quizás aún permanece en sus inicios. Pero por medio de ella se quiere alcanzar la última etapa de independencia frente a un orden que nos fué establecido, en busca de lo que podemos llamar nuestra mexicaniđad.

Nuestro pensamiento, como vamos a ver, irá expresando estas etapas de nuestra historia. Su preocupación girará en torno a los problemas en que dichas etapas se irán planteando. El instrumental para resolver tales problemas será importado, pero no asíla preocupación y las soluciones que en cada caso se irán dando. Con dicho instrumental se defenderán o atacáránosituaciones Ipropiassde México. No se va a pretender,J como erróneamente se ha creído, imponer a la realidad mexicana unas determinadas concepciones filosóficas; todo lo contrario, lo que se hará será buscar aquellas concepciones filosóficas que convengan a esta realidad. La realidad no será sacrificada a las ideas, sino estas adaptadas a la realidad. Esta realidad la formarán los diversos intereses en pugna, los cuales buscarán en las ideas su propia justificación. A una concepción filosófica estática, que pretendía justificar la permanencia de los privilegios de un determinado grupo o clase social, veremos oponer una concepción dinámica que negará tal permanencia y justificará la acción de otros grupos por alcanzar privilegios que no posee. Así veremos cómo la adopción de determinadas con- 
cepciones filosóficas va a estar determinada por la necesidad de realizar una acción histórica de carácter ofensivo o defensivo; para atacar una determinada situación histórica o para defenderla. Y como es de suponer, estas situaciones son situaciones propias de la historia mexicana.

La filosofía de la Colonia lo fué la Escolástica; pero no era esta ya la filosofía creadora de un Tomás de Aquino en el siglo XIII, ni tan siquiera la renovada filosofía de un Suárez en el XVI. La Escolástica que se imponía en nuestras tierras, como se había impuesto en la Metrópoli, era ya una filosofía anquilosada, endurecida en la defensa negativa que hacía de los intereses del mundo medioeval en pugna con el Modernismo. Ya no era la filosofía creadora de un orden universal, sino la defensora de un orden que se derrumbaba. Ya tan sólo negaba, daba un "no" a todo la que fuese contrario al orden que había creado.

La idea del orden medioeval creada por da escolástica fué impuesta en la mente de los mexicanos. Con ella se imponía el respeto y sumisión al orden teocrático establecido por España. Se formaban súbditos fieles de la teocracia española y creyentes no menos fieles de su clero. Samuel Ramos en su excelente Historia de la Filosofía en México muestra cómo muchas de las actividades del mexicano fueron deformadas si no ahogadas, poniendo, inclusive, una marca aún permanente en el carácter de los mexicanos, y por qué no decirlo, en el carácter de los hispanoamericanos... "La filosofía escolástica -dice Ramos-, más o menos directamente es uno de los factores que han modelado el carácter mexicano, el cual se distingue todavía por una cierta falta de voluntad propia, por un hábito inconsciente de esperarlo to- 


\section{$-248-$}

do de Dios o del gubierno". Inclusive la tutela mental a que nos hemos acostumbrado, la deduce Ranos de esta educación.

Pese a todos los cercos impuestos a la Nueva España, la Modernidad con sus ideas empezó a infiltrarse en la mentalidad mexicana. Las nuevas ideas empezaron a hacer su aparición en el mismo campo de la Iglesia. Esta, encargada de cuidar de que nada contagiase estas tierras, sufría el contagio. Es extraordinario ver cómo los primeros próceres de la libertad de conciencia en nuestra América son hombres de Iglesia. Tal cosa se explica, la Iglesia era en estas tierras y en España la única entidad cultural; ella era la que señalaba lo que convenía y lo que no convenía dentro de la cultura. Sus hombres eran los que estaban en más inmediata relación con el mundo de las ideas y los más expuestos a sufrir el contagio de la evolución de éstas. Frente a una manera de pensar que ya no creaba, sino que. se conformaba con repetir fórmulas que no concernían ya a una realidad cambiante, estos hombres empezaron a dudar. Sin dejar de ser creyentes empezaron a sufrir la evolución que la mentalidad europea había sufrido al entrar en el Modernismo. No dudaban de Dios ni de sus obras; pero dudaban que el orden predicado fuese el impuesto por Dios y obra suya. Se empezaba a separar lo Divino de lo humano. La razón, después de todo, era un instrumento donado por Dios al hombre para que hiciese uso de ella en el mundo donde había sido creado. No debían confundirse los dos terrenos, uno era el de lo divino, otro el de lo humano. Había que distinguir también entre las ciencias para cada uno de estos mundos. Para el primero el hombre era demasiado poco y sería inútil todo cuanto hiciese por alcanzar tal ciencia, para esto bastaba la fé. No le quedaba sino el segundo, para el cual le había sido dada la razón. Así quedaba afian- 
zada la fé al mismo tiempo que se robustecía la capacidad del hombre para actuar en su mundo.

Establecidas las distancias, las doctrinas de Descartes, Bacon, Locke y Gassendi servirían como pivote para reformar la educación en la nueva España. "Las voces que se levantaban fuera, para combatir la escolástica en las aulas - dice Ramos - eran ya tan numerosas que al fín las autoridades eclesiásticas tenían que ceder." En I $7 S_{4}$, un jesuita, Andrés de Guevara inicia una nueva etapa en la filosofía en la nueva España. En su libro Instituciones Philosóphicas establece la distinción entre lo que llama la filosofía propiamente dicha o metafísica y las ciencias inferiores. En adelante ya no se siguió aplicando el mismo método deductivo de metafísica a los conocimientos esencialmente experimentales. Uno era el campo de la metafísica y otro el campo de la experiencia. El Padre Guevara ataca violentamente a la escolástica considerando "bárbaro, inculto y horrendo su lenguaje, inútiles y vanas sus cuestiones, tiránico e insoportable su dominio." Sin negarse el mundo de lo metafísico, se abría el campo al mundo de lo experimental. La distinción entre estos dos mundos pronto pondrásen tela de juicio el derecho divino de una Nación para dominar a otras. Era el primer paso hacia la Independencia política de México.

Juan Benito Díaz de Gamarra es el pensador considerado por uno de nuestros historiadores como el "precursor ideológico de nuestra independencia". Y sin embargo, nunca hizo política, se limitó a filosofar sobre temas aparentemente abstractos. Su tema principal lo fué el de la Razón. En su viaje por Europa conoció la filosofía moderna y se hizo su partidario y propagandista. Gamarra se apoya principalmente en Descartes al propugnar por la autonomía de la razón frente al principio de autoridad sostenido por la escolástica. La filosofía - nos dice -, es el conocimiento 
de lo verdadero, lo bueno y lo honesto, obtenido por la sola luz de la razón y el ejercicio del razonamiento". También establece un doble tipo de conocimiento: el cle la fé y el de la experiencia. Dice: "El hombre sabio se contenta con creer a pirño cerrado todo aquello que es cierto por divina revelación, o por los otros testimonios de nuestra religión sacrosanta que es todo lo que nos propone nuestra madre la Santa Iglesia..." Hasta aquí habla del conocimiento proveniente de la revelación y la fé; pero a continuación dice, existe otro conocimiento, "todo lo que es cierto por física evidencia, o por razones incontrastables”. A lo primero llama fé divina, a lo segundo fé humana. El verdadero filósofo es para Gamarra el que sólo admite en las ciencias naturales aquello que la razón y la experiencia no contradicen, o añaden, no está en oposición a los dogmas de la fé. Pero cuando se dice esto último ya se ha separado el mundo de la fé del mundo de lo experimental. En esta forma un católico, sin dejar de ser católico, dignifica a la razón humana. Este paso ya lo había enseñado Descartes al mostrar el poder de la razón sin negar la existencia de Dios. La misno razón al querer alcanzar un saber divino sin lograrlo, estaba mostrando la existencia de una razón que tenía tal poder. Idea que encontramos reflejada en las palabras de Gamarra al decir: "La propia vanidad y el espíritu de partido nos hacen obstinados en nuestras opiniones, y no permiten que el hombre ducle y reconozca que ignora aquello que realmente no sabe o que jamás podrá saber.' Gamarra llamaba a su filosofía eclecticismo. En ella no valian principios de autoridad. "No se admita... con obstinación-dice-, como cierto y evidente, aquello que sólo es probable, ni se nos venda por demostración matemática, lo que no es ni puede serlo, sin otro fundamento que el haberlo enseñado así nuestros 
maestros." "Felices los filósofos eclécticos -concluía diciendo-, que imitando a las abejas, buscan de flö en flor el suave néctar de la ciencia". La independencia de la razón era expresada plenamente al afirmar que el verdadero filósofo, el verdadero amante de la Verdad era aquél que se consagraba a buscarla sin confesar secta alguna, "ni la peripatética, ni la platónica, ni la leibiciana, ni la newtoniana." Esto equivalía a una clarinada de independencia. El mexicano era invitado a pensar por sí mismo en lo que a su mundo se refería. Y dentro de este su mundo estaba su propia Nación con derecho a ser independiente como independiente era su razón. El mexicano, sin negar sus hábitos cristianos, sin negar su fé como religioso, podría discutir problemas de experiencia inmediata como lo eran los derechos de España a gobernar México, los cuales se apoyaban en un principio de autoridad. En este sentido se orientaría más tarde la independencia politica deMéxico; sin romper con la Iglesia. México se independizaría de España. La oposición a la Iglesia será motivo de otra etapa libertaria.

-E1 conocimiento detDescartes, Gassendi, Condillac, Newton y Locke que abrian brecha entre los propios hombres de la Iglesia, preparó la mente de los mexicanos para entender a los filósofos de la Revolución Francesa. Establecida la capacidad de la razón humana, el hombre y sus derechos habrían de ser los temas discutidos por la intelectualidad mexicana. La revolución filosófica conducía a la revolución política. A esto se sumaba un cambio político en la Metrópoli española, la subida al trono de los Borbones que abrían las puertas de la ya resquebrajada ciudadela fundada por los Habsburgos. Con la política de Carlos III se abrió el Imperio Español a las ideas del mundo moderno. A la nueva España llegaron toda clase de libros y al finalizar el siglo XVIII se conocía ya a los Enciclopedistas. La 
lucha contra la filosofía peripatética recrudeció, mientras la filosofia experimental iba ganando rápidamente mayor campo. Los mexicanos iban sintiéndose cada vez más dueños de sí y con mayores derechos, cada vez menos dependientes de la Metrópoli.

A este sentimiento de independencia de los mexicanos colaboraría brillantemente una pléyade de sacerdotes jesuitas. Es extraño ver cómo la orden creada para defender y sostener la Cristianidad, que cede terreno a la Modernidad, colabora en el caso mexicano al triunfo de la segunda. A fuerza de atacar el enemigo en su propio terreno, éste les iba dominando. El modernismo se ha significado por poner el acento en e! terreno de lo inmanente a diferencia de la Edad Media que ponía el acento en el terreno de lo trascendente. Uno ponía el acento en el mundo de lo experimental, otro en el de lo revelado. El uno crea la ciencia, el otro la metafísica; uno se apoya en la inducción, el otro en la deducción, o en otras palabras, en uno se quedaba el hombre solo, atenido a sus propias fuerzas, mientras que en el otro el hombre dependialde lacvoluntadedivina. El cartesianismo y todo el Racionalismo del siglo XVIIsfué un puente entre estas dos concepciones de la vida. El hombre quiere el dominio del mundo, pero sin abandonar su ligamen con Dios. En el siglo XVIII se inicia la plena descristianización del hombre: Dios desaparece del horizonte del hombre moderno como algo inalcanzable e innecesario. El hombre nada sabe ni puede saber de Dios; las ideas que sobre él tiene no son sino producto de algo humano, tan humano como es para Hume el miedo.

En adelante se abandona la metafísica y se pone el acento en lo experimental, lo inmanente. La temática de las investigaciones del pensamiento cambia; los grandes temas metafísicos dejan su lugar a la física experimental, la his- 


\section{$-253-$}

toria, la literatura, el arte. Lo importante va a ser ahora el hombre y el mundo en que se encuentra. En la Compañía de Jesús observamos también este cambio de temática, el paso de un siglo a otro. Mientras en el siglo XVII nos encontramos a un gran metafísico como lo fué Francisco Suárez, en el siglo XVIII los temas de la metafísica dejan su lugar a las investigaciones históricas, cientificas, literarias. En España, entre otros están los nombres de los jesuitas Exímeno, Andrés e Isla.

En México, los jesuitas dan su aportación a la constitución de la nacionalidad mexicana con sus investigaciones, también puestas en el terreno de los temas inmanentes. Francisco Javier Clavijero escribe una Historia Antigua de Méjico, aplicando la crítica científica para valorizar los datos reunidos reconstruyendo el pasado indígena. Otro jesuita, Rafael Landivar escribe un libro poético sobre la Tierra Mexicana a la que titula Rusticatio Mexicana. "Los efectos de este movimiento científico - dice Samuel Ramos-, no consistieron simplemente en renoyar y enriquecer el acervo de los conocimientos, sino en algo mucho más importante aún, en dar a los mexicanos conciencia de sí mismos. La historia, la filosofía, la erudición, la biología, las ciencias físicas iban revelando los rasgos peculiares de México. El país estaba maduro para su independencia política.

Los próceres de la Independencia política de México han bebido sus ideas en estas fuentes al parecer apolíticas. Pero por ellas su mente se encontraba preparada para recibir las ideas revolucionarias de Voltaire, Rousseau, Montesquieu. El padre de la Independencia, un sacerdote, don Miguel $\mathrm{Hi}$ dalgo, había iniciado su carrera intelectual en el Colegio de San Nicolás en Morelia, cuyos estudios filosóficos han sido reformados por el ya citado jesuita Clavijero. Cuando los jesuitas fueron expulsados, Hidalgo se encontraba 
a la mitad de su carrera. Pero su mente había quedado preparada para las ideas de emancipación que esgrimiría más tarde. Otro de los próceres de la Independencia, don Ignacio Aldama había recibido su instrucción filosófica teniendo como texto los Elcmentos de Filosofía Moderna de Benito Díaz de Gamarra. Sin embargo, como ya se ha repetido, el sentido de la emancipación política no fué acompañado de un sentido de emancipación religiosa. Los mexicanos se liberaban de España, pero no de su religión ni de la organización social por ella impuesta. Esto sería obra de nuevas emancipaciones.

Obtenida la independencia política de México, una nueva lucha había de encenderse: la lucha entre liberales y conservadores. Era esta la continuación de la lucha emancipadora de México. Las ideas sembradas en la mente de los mexicanos continuaban su evolución. Libres de la tutela española, ahora había que libertarse de la tutela del Clero empeñado en mantener su predominio sobre la Nación mexicana, como la había tenido sobre el Imperio español.

Aliada a la Iglesia estaba la casta militar, que había intervenido en la lucha de independencia política de México cuando así convino a sus intereses. Dicha casta cobraba con creces su oportuna intervención. Clero y milicia se confabulaban para maritener el orden establecido por España; pero sin España. Frente a estos grupos herederos de la $\mathrm{Me}-$ trópoli española, se alza un nuevo grupo social que, siguiendo nuestra referencia a la influencia de las ideas de Europa en México, podemos llamar fruto de la semilla modernista sembrado en este país; este grupo social se ha llamado a sí mismo "burguesía mexicana"; y que a semejanza de la gran burguesía europea pretendió establecer un nuevo or-- 
den basado en las ideas inmanentes del Modernismo. Este grupo, nos dice Justo Sierra, lo formaban los hombres de la clase media de los estados, los que habían pasado por los colegios, los que tenían lleno de ensueño el cerebro, de ambiciones el corazón y de apetitos el estómago, "la burguesía dió oficiales, generales, tribunos, ministros, mártires y vencedores a la nueva causa." Estos eran los hombres que se enfrentaron en la nueva lucha.

El Dr. José María Luis Mora fué el primer teórico de este grupo social. En él se nota la influencia, entre otros, de Bentham y Benjamín Constant; así como la ideología de Destutt, de Tracy y Cabanis. El utilitarismo de Bentham fué hábilmente adaptado por Mora a las circunstancias mexicanas, preparando, en la teoría la revolución que poco tiempo después había de realizar la llamada burguesía mexicana. Mora inicia la lucha que habría de terminar con el triunfo de este grupo social. Mora presenta la lucha entre liberales y conservadores como la lucha entre las fuerzas del Progreso y las del retroceso. Existe una marcha del progreso y una marcha del retroceso. La marcha del progreso era aquella que tenía como fin lacocupación de dos bienes del clero; la abolición de los privilegios de clase y los de la milicia; así como la difusión de la educación pública en las clases populares, en forma absolutamente independiente del clero; absoluta libertad de opiniones e igualdad de los extranjeros con los naturales en los derechos civiles. En cambio la marcha del retroceso era aquella que pretendía abolir lo poco que se había heiho por el progreso.

Los intereses de cuerpo de la milicia y el clero, dirá Mora, han hecho del Estado un instrumento al servicio de los mismos. El Estado no cumple su misión, no sirve a la sociedad, sino a facciones que se han apoderado de él. Para estas facciones el Estado no es sino una rica mina de la cual 


\section{$-256-$}

extraen todos sus privilegios, de aquí que sean enemigos de todo cambio o progreso porque alteraría su posición social y con ella sus privilegios. Mora hace una dura crítica a la costumbre muy hispanoamericana de esperarlo todo del Gobierno, de querer vivir de él, convirtiéndolo en botín de guerra. Existen fuentes inexplotadas de riqueza y bienestar que debian ser explotadas, el Estado no puede ser esta fuente; el Estado no es sino un instrumento al servicio de la sociedad. Los mexicanos deben trabajar, poner industrias y enriquecerse, esta es la única verdadera fuente de privilegios que conduce al progreso al mismo tiempo que dé independencia al individuo. El Estado deberá tener como misión la de ser guardián de los frutos de estos legítimos esfuerzos por la prosperidad personal que lo es también de la Nación. Así es como se sostenía la doctrina de lo que debería ser en el futuro una poderosa burguesía mexicana.

El clero y la milicia no deberían desaparecer, sino ser puestos al servicio de la sociedad. Ambos eran necesarios a la sociedad; pero era menester que se limitasen a cumplir su misión. Dice Mora, es menester que cada ciudadano se pregunte si el clero y la nilicia existen" para el pueblo o el pueblo para el clero y la milicia. Ambos han sido creados para satisfacer las necesidades de la sociedad; pero no la sociedad para satisfacer las necesidades del clero y la milicia. Que cada mexicano cumpla con la misión que le corresponda en la sociedad. Esta tesis se va a expresar en la fórmula de Benito Juárez: "El respeto al derecho ajeno es la paz."

El clero no ha comprendido esto, su misión que es servir al espíritu; su poder que está en lo espiritual ha sido aprovechado para servir sus intereses de cuerpo, sus intereses de grupo social. Ha querido hacer de su poder espiritual un poder material. De aquí la necesidad de separarlo 
de sus relaciones con el Estado. Estado e Iglesia católica deben separarse, uno es el poder material y el otro el espiritual. El primero no debe ser instrumento del segundo, sino instrumento de la sociedad. Dentro de la sociedad cada individuo puede pensar como mejor le plazca, a lo único que no tiene derecho es a imponer sus ideas tratando de justificar privilegios que no han alcanzado con su propio esfuerzo. Contra la tesis que sostiene que determinados privilegios son un don divino, o la tesis que concede privilegios a los caudillos ó héroes nacionales, está la nueva tesis de la burguesía mexicana, la del trabajo, la del esfuerzo personal: cada hombre tiene derecho a poseer aquello que es capaz de lograr por su propio esfuerzo. Estos nuevos hombres se consideran herederos del trabajo, no de Dios. El Estado, como guardián del orden que permite el desarrollo individual, nada tiene que ver con el poder espiritual. De su conciencia cada individuo es su propio dueño; puede ser católico, protestante o masón, el Estado no tiene por qué intervenir aquí, sólo interyendrá cuando no se respete el derecho de los demás.

Benito Juáreż llevaráa anlalirealización estas teorías. En la Constitución de 1857 , realizada por el movimiento revolucionario llamado de Reforma, cristalizarán tales ideas. Con esta revolución se daba un paso más, el de la independencia religiosa o libertad de conciencia. En esta Constitución se ha establecido la separación entre la Iglesia y el Estado que subsiste hasta nuestros días. El catolicismo dejaba de ser religión de Estado, cada mexicano era en adelante libre para tener la religión que quisiese y para pensar libremente.

El año I 867 , diez años después de promulgada la Constitución, las fuerzas liberales se imponían en todo el país. Las fuerzas invasoras francesas de Napoleón III, traídas 
por los conservadores que así traicionaban a su país, tenían que abandonarlo. $\mathrm{Y}$ el iluso emperador Maximiliano de Habsburgo era ejecutado con otros jefes conservadores en el Cerro de las Campanas. Este mismo año en la ciudad de Guadalajara, un hombre, el Dr. Gabino Barreda, pronunciaba una Oración Cícica en la que se hacía una interpretación de la Historia de México. Dicha interpretación se enfocaba de acuerdo con la tesis positivista de los tres estados de Comte. El triunfo de la República mexicana era el triunfo del espíritu positivo en lucha contra las fuerzas teológicas y feudales formadas por el clero y los caudillos militares. En México, el espíritu positivo, que había ya vencido en Europa, ganába su última batalla. El fin perseguido por la revolución en México lo era la emancipación mental. Sin la marcha progresiva del espíritu positivo, decía Barreda, no podría explicarse la historia de México. Era imposible comprender como un pueblo inerme pudo vencer a un "clero armado a la vez con los rayos del cielo y las penas de la tierra, jefe supremo de la educación universal". Esta explicación, seguía diciendo, se encuentra en "la emancipación mental, caracterizada porila gradialedecadencia de las doctrinas antiguas, y su progresiva substitución por las modernas." El clero no había comprendido esta ley de la emancipación mental; de haberlo comprendido no se habría opuesto o al menos habría tratado de apagar las luces que en el campo de la física se encendieron. Quien quita el rayo a los dioses puede también quitarles el dominio de los hombres. Las luces de la ciencia positiva iluminaban también el terreno de la política, arrancando su dominio a la teología. En la lucha que México había sostenido contra Napoleón III y las fuerzas regresivas del país, éste había encarnado a toda la fuerza positiva de la humanidad. Su triunfo no era sólo triunfo mexicano, sino triunfo del progreso de esta $\mathrm{Hu-}$ 
manidad. Cuando Europa entera había sucumbido ante las fuerzas regresivas, México se enfrenta a ellas y con su resistencia lograba la victoria del espíritu progresivo. "En este conflicto- dice Barreda-, entre el retroceso europeo y la civilización americana, en esta lucha del principio monárquico contra el principio republicano, en este último esfuerzo del fanatismo contra la emancipación de la mente, los republicanos de México se encontraban solos contra el orbe entero". Es así como con el triunfo de la llamada revolución de Reforma en México, se alcanzaba la segunda fase de la emancipación frente a la Colonia, la emancipación de la conciencia o mental.

Después del triunfo de la burguesía mexicana se hacía urgente el establecimiento del orden. Pero no bastaba un orden superficial, era menester un nuevo orden que tuviese como base la conciencia de los mexicanos. Era menester una nueva educación que desplazase a la establecida por el clero. Para sustituir a una formación teológica era menester lo que se podía llamar cuna educación spositiva. Gabino Barreda fué el hombre indicado para la reforma. En su Oración Cícica había planteado el problema. Benito Juárez le encargó de hacer la reforma educativa. Gabino Barreda había escuchado en París las lecciones filosóficas de Comte. Ahora esta doctrina iba a ser adaptada a las necesidades cle México. Eran las que se necesitaban para desplazar a las que sostenía la Iglesia Católica.

El positivismo fué al mismo tiempo un instrumento para negar las ideas del derrotado régimen conservador $y$ oponerse a las peligrosas ideas de los liberales que aún sostenían ideas combativas. La lucha había terminado, las ideas de libertad absoluta sostenidas por los viejos liberales eran 


\section{$-260-$}

peligrosas. Había que enfrentarse tanto a las fuerzas retroactivas de los conservadores, como a las anárquicas de los liberales. Dentro de la denominación positivista los primeros eran la expresión de las fuerzas teolóscicas, los segundos de las metafísicas. En México se había cumplido también la ley de los tres estados: la Colonia había sido la expresión del estado teológico; la lucha liberal contra la Colonia, la expresión del estado metafísico; ahora se había llegado al estado positivo, el de un nuevo orden que substituyese al teológico. Sin embärgo, las fuerzas revolucionarias no querían comprender que su misión había terminado y se empeñaban en sostener ideas que no eran sino expresión de la anarquía. La anarquía sólo era buena para destruir un orden; pero no para construir otro. La burguesía mexicana quería orden a cualquier precio, en adelante sus opositores serán los viejos liberales y los conservadores. Gabino $\mathrm{Ba}$ rreda por medio del positivismo formaba una nueva generación dispuesta a imponer un nuevo orden. Un nuevo grupo de conservadores aparecía en la palestra política de México; pero estos ya no invocaban el mito de la divinidad, sino un nuevo mito: la Ciencia.

Una nueva idea de libertad se empezaba a sostener. Ya no era la libertad como la habian entendido los liberales mexicanos: libertad de pensar y actuar como se quisiese sin otro límite que el respeto a la libertad de los demás. Barreda, al hablar sobre la moral hará otra definición de la libertad. Se enfrenta a la tesis liberal de la libertad que la define como "un dejar hacer". Si tal libertad existiese, dice Barreda, sería tan inmoral como absurda y haría imposible todo orden. El orden no es incompatible con la libertad. La libertad, dice, consiste en someterse plenamente a la ley de orden que deba regirla. Algo es libre cuando sigue su curso normal, cuando no encuentra obstáculos que desvíen su cur- 
so natural, su propia ley, su propio orden. Barreda pone un ejemplo de física y dice: cuando se habla de un cuerpo que cae libromente, no se habla de un cuerpo que cae por donde le de la gana, sino que cae siguiendo las leyes de la gravedad; en cambio no es libre si encuentra algún obstáculo en su caída que le desvíe. Esta es para los positivistas la verdadera libertad, la que la ciencia enseña. El hombre no es libre para hacer lo que quiera, sino aquello que convenga a la sociedad que es la que impone sus leyes.

A esta ley se suma la del progreso del positivista Herbert Spencer. El progreso que conduce a la libertad del individuo, la libertad predicada por los liberales mexicanos, es algo que se obtiene por ciolución, no por revolución. Jusro Sierra, teórico de la nueva burguesía mexicana dice estar de acuerdo con Spencer cuando expresa "que la sociedad, como todo organismo, está sujeta a las leyes necesarias de la evolución; que éstas en su parte esencial consisten en un doble movimiento de integración y de diferenciación, en una marcha de lo homogéneo a lo heterogéneo, de lo incoherente a lo coherente, de lo definido a lo indefinido", es decir, continúa Sierra, que en todo cuerpo urorganismo en la medida que se integra o se unifica más, sus partes más se diferencian y más se especializan. En este doble movimiento está el perfeccionamiento del organismo, su progreso." Esta idea llevada a la política mexicana conducía a lo siguiente: para poder alcanzar la plena libertad individual, era menester alcanzar previamente un pleno orden social. México aún no había alcanzado este orden, por ende no podía alcanzar la libertád que predican los liberales, tal cosa era utópica. Primero habia que ordenar al pueblo mexicano, que la libertad se daría dentro del mismo orden. Ahora bien, esto es, dicen los positivistas, lo que intentan hacer nuestros políticos formados en las ideas positivistas. Ellos son los encargados de ha- 
cer realidad la libertad estableciendo el orden; ellos establecerán las condiciones que hacen posible la libertad; ellos son los hombres de ciencia que, de acuerdo con métodos científicos, harán su realización. Pronto el pueblo dará a estos el mote despectivo de partido de los "Científicos". En nombre del orden positivo estos hombres reclamarán un tirano honrado que impusiese el orden. Este tirano había de llamarse Porfirio Díaz y su época el Porfirismo.

Con Porfirio Díaz el orden anhelado por la burguesía mexicana era un hecho. No había quien le disputase el puesto directo. Porfirio Díaz tenía el poder político y la burguesía el poder económico. Uno gobernaba, los otros se enriquecían, y la marcha de la evolución que había de conducir a la libertad se hacía cada vez más lenta. Una nueva idea de libertad surgía para hacer juego a sus intereses: la de la libertad de enriquecimiento unida a la tesis darwiniana del derecho del más fuerte. Todos los mexicanos tenían derecho a enriquecerse; pero unos lo podían más que otros, el más fuerte era el más rico y el que teñía más derecho a que se le protegiese, puesto que la riqueza era producto de su esfuerzo. El estado tenía esta misión. En esto consistía el progreso en México: cuanto más ricos eran sus individuos, más progresaba el país. Así se justificaba el grupo que poseía bienes susceptibles de ser aumentados.

Preocupada sólo por su enriquecimiento, la burguesía mexicana había respetado el status social establecido por la Colonia, el cual tenía como base el dominio de la tierra. La fuente del enriquecimiento lo seguía siendo la tierra y el explotado el indígena. Las tierras arrebatadas a la Iglesia no volvieron a sus dueños sino repartidas entre nuevos explotadores. Se formaron gigantescos latifundios. El latifundista tomó el lugar del conquistador y del clero; el hom- 
bre del campo siguió en la misma escala social en que le había puesto la conquista. Trabajaba la tierra pero no tenía derecho a sus frutos. La burguesía mexicana mantuvo el mismo orden social de la Colonia pero justificándolo con el mito de la Ciencia, que como hemos visto sustituía al de la Divinidad. No realizó el ideal de Mora y de Juárez, de una burguesía enriquecida por la explotación industrial. Nuestra burguesía fué latifundista y burócrata; Incapaz de industrializar el país, entregó la explotación de la industria mexicana a la poderosa Burguesía Europea, de la cual no pudo ser otra cosa que su amanuense. Abogados que servían los intereses de las grandes compañías europeas; políticos que traficaban con las concesiones industriales y latifundistas que vivían del fruto de tierras que ni siquiera conocían; tal era nuestra burguesía que en las ideas positivas había buscado su justificación.

En I9Io estallaba en México uña tercera revolución. Dicha revolución tuvo un doble cariz, dos fuerzas la provocaron: una lo fué la propia burguesía mexicana que había ido siendo desplazada por un grupo de ella surgido, por el que de acuerdo con su tesis era el más hábil, el más fuerte en esa lucha por el enriquecimiento. En torno a Porfirio Díaz se había formado una oligarquía que acaparaba toda la riqueza del país. La burguesía mexicana que había sido desplazada retira su apoyo al régimen porfirista y exige su cambio. El lema de su revolución fué "Sufragio efectivo. No reelección". Pero a su lado se levantaba también otra fuerza hasta entonces impasible y engañada, la del trabajador del campo que se alzaba al grito de "Libertad y Tierras". No se rebelaba simplemente contra el Porfirismo y su oli- 
garquía, sino contra un orden basado en el latifundio. La burguesía quería una revolución política que desplazase a un régimen que ya no convenía a sus intereses: las clases explotadas de México exigen una revolución social que altere el status establecido por la Colonia. La revolución, en cuyo desarrollo se encuentra aún México, altera este status destruyendo la econonía colonial del terrateniente y latifundista. Con ella se inicia un gran reparto de tierras entre los que las trabajaban. No vamos a negar que hay defectos en su realización; pero de hecho se ha iniciado la última etapa de emancipación frente a la Colonia. El indio, deja de ser la clase explotada y se le pone a la altura de todos los mexicanos, puesto que forma el grueso de la población mexicana. En vez de destruírsele y explotársele, se le asimila transformándolo en una fuerza activa. La mexicanidad empieza a ser un hecho.

Al mismo tiempo que se iniciaba la revolución que había de tener como fín cambiar el status social de México, se inicia una crítica contra las doctrinas positivistas en que se basaba nuestraburguesíacEl Exupo que encabeza la lucha contra el positivismo es elconocido con el nombre de la Generación del Ateneo de la Juventud. Este grupo lo forman, entre otros, hombres como José Vasconcelos, Antonio Caso y Alfonso Reyes. A la filosofía positivista se opondrá una nueva filosofía dinámica. Los positivistas mexicanos, apoyándose en la experiencia de lo material habían tratado de demostrar la inmutabilidad de la materia, que si bien evoluciona, lo hace de acuerdo con un orden rígido que le es propio y no puede ser alterado: el orden que establece la naturaleza. Frente a esta tesis se opondrá una nueva generación mostrando, con el apoyo de Bergson, Boutroux y otros, la mutabilidad de la propia materia, y con ella la del régimen que, en sus leyes, quería justificarse. A una filosofía que 
había encontrado un nuevo orden inmutable se enfrentará una filosofía dinámica, predicando el cambio de todo, inclusive el de la materia. "Nada definitivo podemos esperar de la materia -dice Vasconcelos-. Ella es, al contrario, el tipo de lo perecedero ... los que creyeron en el retorno eterno de los fenómenos se han equivocado, porque nada vuelve a su primitivo estado, sino que en cada momento, lo más importante de la energía se pierde en el silencio, en la quietud de lo inerte." De acuerdo con Bergson, sigue diciendo Vasconcelos "la materia es un movimiento de descenso, de caída." Lo que verdaderamente progresa, lo que se transforma es la vida, "la vida es una reacción, un movimiento contrariante del descenso; un impulso que tiende a desprenderse del dominio de las leyes naturales." Al concepto de libertad positivista se opondrá un concepto más alto: el de la libertad, una libertad creadora como la misma vida, la que llamarán libertad de espíritu. La libertad de espíritu no es la libertad de la materia sometida a leyes; es precisamente libre de estas leyes. Cuanto más se aleja de las leyes desgradantes de la materia, es más libre. Y esta libertad, diría Vasconcelos, se convertirá en desinterés. Libertad quierer decir capacidad de crear libremnte, esto es, desinteresadamente, por exuberancia de fuerza creadora. Al egoísmo calculador del positivismo se opone el desinterés. El positivismo era calculador y egoísta por limitado; la nueva filosofía va a predicar el desinterés que ofrece lo ilimitado. Lo estrecho conduce al egoísmo por lo mucho que le falta, lo ilimitado a la generosidad por lo mucho que le sobra. El tema del desinterés da materia a uno de los más sugestivos y originales ensayos de otro miembro de la generación. Antonio Caso escribe el libro titulado La existencia como econonomía, como desinterés y como caridad. En el terreno de lo social se com- 
prenderá el cambio que tal concepción filosófica implicaba. A una concepción social limitada a proteger los intereses de un grupo social; se opondrá una concepción generosa, abierta a toda reivindicación social, puesto que ahora tienen cabida todos los hombres, todas las clases sociales. Empieza así el proceso de asimilación de todos los mexicanos, sin las discriminaciones establecidas por la Colonia. Vasconcelos es uno de los paladines de esta asimilación al iniciar la gran tarea educativa de las clases que habían sido alejadas de la educación, para hacer de ellas simples instrumentos de explotación. Caso y Reyes también darán su aporte en esta tarea asimiladora. Al lado de ellos artistas como Orozco, Rivera, Siqueiros y otros muchos, en la pintura, al igual que poetas como López Velarde y novelistas como Mariano Azuela, buscarán la expresión de 10 mexicano, cacla vez más libre de todo colionalismo artístico, como lo iba siendo de lo social.

A esta última actitud de la búsqueda de la mexicanidad responde lả preocupación filosóficas de nuestro tiempo. El paladín de estacactitud haisido Samuel Ramos que ha convertido en preocupación filosófica la realidad mexicana; fruto de sus primeras preocupaciones lo ha sido ese hermoso y discutido trabajo titulado El Perfil del Hombre y la Cultura de México, en el que los problemas mexicanos de la cultura son vistos desde una altura filosófica, tratando de encontrar la realidad de lo propiamente mexicano. La raíz y fuente filosófica de esta actitud nos las describe Ramos sobre la Filosofía en México, diciendo: "Era un movimiento nacionalista que se extendía poco a poco en la cultura mexicana. En la poesía con Ramón López Velarde, en la pintura con Diego Rivera, en la novela con Mariano Azuela. El mismo Vasconcelos, desde el ministerio de educación, había hablado de for- 
mar una cultura propia y fomentaba todos los intentos que se comprendían en esa dirección. Entre tanto la filosofía parecía no caber dentro de ese cuadro ideal del nacionalismo porque ella ha pretendido colocarse en el punto de vista universal humano, rebelde a las determinaciones concretas del espacio y tiempo, es decir, a la historia. Ortega y Gasset vino ... a resolver el problema mostrando la historicidad de la filosofía en el Tema de Nucstiro Ticmpo. Reuniendo estas ideas con algunas utras que había expuesto en las Meditaciones del Quijote, aquella generación mexicana encontraba la justificación epistemológica de una filosofía nacional."

Esta actitud encabezada por Samuel Ramos vino a ser reforzada por la emigración de un destacado grupo de intelectuales españoles, discípulos de Ortega y Gasset o de la filosofía alemana en que éste se había formado. No se trata ahora de imitar o seguir estas ideas, sino, como dice Ramos, de hacer de ellas un instrumento consciente al servicio de la solución de nuestros problemas. Como se ha visto, por este breve panorama, las ideas inmportadas han estado siempre al servicio de nuestra realidad; pero inconscientemente, ahora se les toma conscientemente y se pretende hacer patente lo nuestro. No es una actitud de desprecio o de nacionalismo a ultranza el que nos guía, sino un sentido de responsabilidad. Creemos que ha llegado el momento de hacernos. responsables de nuestros actos; creemos que ha llegado el momento de colaborar en las tareas de la Cultura Occidental de la cual somos hijos. Creemos y en esto vale citar las palabras de un mexicano, Alfonso Reyes, que hemos alcanzado la "mayoría de edad". Como americanos queremos nuestro puesto en la cultura para tomar una parte activa en ella. 


\section{BIBLIOGRAFIA}

Samuel Ramos: Mistoria de la Filosofía en Mćxico, Joprenta Universitaria, México 1943.

Leopolbo ZEA : el Positivismo en México, El Colegio de México, México 1943.

Leopoldo Zea: Apogeo y Decadencia del Positivismo en México, El Colegio de México, México 1944.

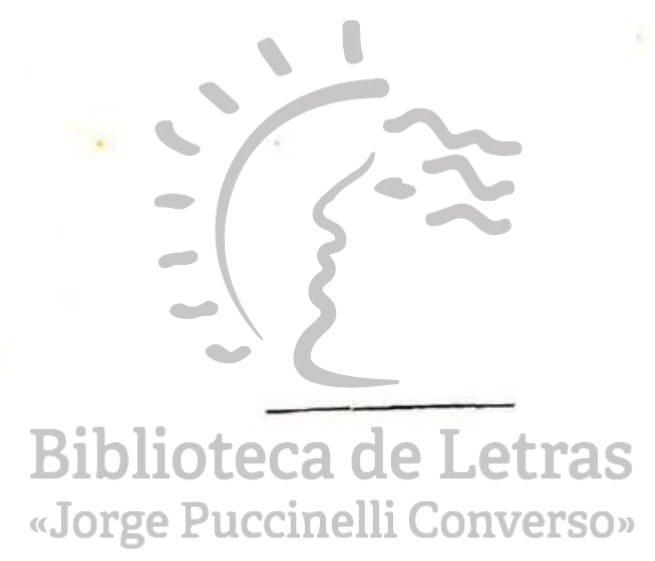

